\title{
Preoperative prognostic nomogram for prophylactic steroid treatment of patients with subclinical Cushing's syndrome
}

\author{
Dengqiang Lin ${ }^{1 \#}$, Jinglai Lin ${ }^{1 \#}$, Xiaoyi $\mathrm{Hu}^{2 \#}$, Yujun Liu ${ }^{2}$, Jianping Zhang ${ }^{2}$, Li Zhang ${ }^{2}$, Jingjing Jiang ${ }^{3}$, \\ Xiaomu Li ${ }^{3}$, Jianming Guo ${ }^{2}$ \\ ${ }^{1}$ Department of Urology, Xiamen Branch, Zhongshan Hospital, Fudan University, Xiamen, China; ${ }^{2}$ Department of Urology, Zhongshan Hospital, \\ Fudan University, Shanghai, China; ${ }^{3}$ Department of Endocrinology, Zhongshan Hospital, Fudan University, Shanghai, China \\ Contributions: (I) Conception and design: D Lin; (II) Administrative support: None; (III) Provision of study materials or patients: None; (IV) \\ Collection and assembly of data: D Lin, J Lin, X Hu; (V) Data analysis and interpretation: D Lin, J Lin; (VI) Manuscript writing: All authors; (VII) \\ Final approval of manuscript: All authors. \\ \#These authors contributed equally to this work. \\ Correspondence to: Yujun Liu. Department of Urology, Zhongshan Hospital, Fudan University, No. 180 Fenglin Road, Shanghai, China. \\ Email: liuyj12018@163.com.
}

\begin{abstract}
Background: Subclinical Cushing's syndrome (SCS) is incidentally detected in a growing number of patients by advanced imaging technology. However, there is no consensus on the clinical management of SCS, especially in terms of whether prophylactic steroid treatment is necessary following adrenalectomy. In this study we developed a model based on preoperative indices for predicting postoperative adrenal insufficiency (AI) that can guide therapeutic decision-making.
\end{abstract}

Methods: A total of 27 patients with SCS who underwent adrenalectomy between August 2016 and August 2019 were enrolled and divided into AI and non-AI groups. Cox proportional hazards regression and least absolute shrinkage and selection operator analyses were performed to select relevant clinical parameters. The predictive performance of our model was evaluated by time-dependent receiver operating characteristic (ROC) curve and calibration curve analyses.

Results: Five clinical parameters (apolipoprotein A1, neutrophil-lymphocyte ratio, total cholesterol, platelet count, and homocysteine) were identified as the best predictors of replacement therapy (RT). The areas under the ROC curve for our prognostic model were 0.833, 0.945, and 0.967 for 3-, 4-, and 5-day non-(N)RT, respectively. The calibration curve of the 5 independent RT-related markers showed a good fit between nomogram-predicted probability of NRT and actual NRT, suggesting that our model has good predictive value.

Conclusions: Our prognostic nomogram can help clinicians identify patients with AI who would benefit from RT so that timely treatment can be initiated.

Keywords: Subclinical Cushing's syndrome (SCS); Replacement therapy (RT); Adrenal insufficiency (AI);

Nomogram; Receiver operating characteristic (ROC)

Submitted Jul 21, 2020. Accepted for publication Nov 15, 2020.

doi: $10.21037 /$ tau-20-1108

View this article at: http://dx.doi.org/10.21037/tau-20-1108

\section{Introduction}

With the development and extensive application of advanced imaging technologies such as ultrasound, computed tomography, and magnetic resonance imaging, an increasing number of adrenal incidentalomas are discovered in association with unrelated disorders, with a prevalence of $4-7 \%(1,2)$. Up to $50 \%$ of patients with adrenal incidentalomas may have hypercortisolism; the vast majority of such cases are subclinical Cushing's syndrome (SCS) $(3,4)$, which is characterized by abnormal 
biochemical indices of the hypothalamic-pituitary-adrenal (HPA) axis without the overt manifestations (e.g., moon face, buffalo hump, central obesity, plethora, striae rubrae, proximal myopathy, supraclavicular fat pad, thin skin, easy bruising, and unexplained osteoporosis or bone fractures) of Cushing's syndrome (CS) (5-9). Diabetes mellitus (DM), cardiovascular events, hypertension, and vertebral fractures are common in patients with SCS $(8,10,11)$.

There is no consensus on the clinical management of SCS $(3,7)$; because of the absence of classic phenotypic features of CS, standard diagnostic tests for the latter are not applicable to SCS diagnosis (3). It is also unclear which treatment strategy [surgery or conservative (i.e., pharmacologic) treatment] should be considered first or which therapeutic regimen should be adopted prior to or following adrenalectomy (3). Compared to a conservative approach, adrenalectomy can effectively alleviate metabolic disturbances caused by SCS but may lead to adrenal insufficiency (AI) (12-17). Irrespective of cortisol level and the severity of hypercortisolism, most clinicians administer replacement therapy (RT) before, during, and after adrenalectomy $(15,18-23)$; however, some only provide RT when serum cortisol concentration is $<5 \mu \mathrm{g} / \mathrm{dL}(138 \mathrm{nmol} / \mathrm{L})$ and/or when cosyntropin stimulation level is $<18 \mu \mathrm{g} / \mathrm{dL}$ $(497 \mathrm{nmol} / \mathrm{L})$ in the morning after adrenalectomy (24), or to patients with plasma hypocortisolism or AI post surgery $(25,26)$. In our medical team, hydrocortisone $(200 \mathrm{mg})$ is intravenously administered once for AI. Given that acute Addisonian crisis is potentially fatal if untreated (26,27), timely identification of these patients is critical for avoiding adverse events.

The probability of developing postoperative AI is greater in patients with preoperative $1-\mathrm{mg}$ dexamethasone suppression test $(\mathrm{DST})>5 \mu \mathrm{g} / \mathrm{dL}$ (28). Reduced plasma adrenocorticotropic hormone (ACTH) concentration is a candidate marker for AI (29), but is by itself insufficient for diagnosis. Given the relationship between cortisol and inflammation as well as metabolism (i.e., of carbohydrates, lipids, and proteins), in this study we developed a quantitative predictive nomogram for postoperative RT based on a combination of multiple clinical indicators. We present the following article in accordance with the TRIPOD reporting checklist (available at http://dx.doi. org/10.21037/tau-20-1108).

\section{Methods}

\section{Patients and inclusion criteria}

This study was conducted in accordance with Declaration of Helsinki (as revised in 2013). Following approval by Ethics Committee of Zhongshan Hospital affiliated to Fudan University in China (No.2010-70), because of the retrospective nature of the research, the requirement for informed consent was waived. We collected clinical information of 40 patients who underwent adrenalectomy between August 2016 and August 2019 at the Department of Urology of Zhongshan Hospital affiliated with the Medical School of Fudan University in China, and who were subsequently diagnosed with SCS. The inclusion criteria were as follows: (I) adrenal masses detected by imaging; (II) no classic clinical manifestations of CS (i.e., dorsocervical fat pads, moon facies, abdominal striae, proximal myopathy, easy bruising); (III) excess serum or urine cortisol, altered circadian rhythm, or failed DST; (IV) underwent surgery and had a confirmed diagnosis of adrenal adenoma. The study ultimately enrolled 27 patients, who were divided into postsurgical AI $(n=9)$ and non-postsurgical NAI $(n=18)$ groups after adrenalectomy according to the manifestation of specific symptoms. Because of the retrospective nature of the research, the requirement for informed consent was waived.

Because glucocorticoids can affect inflammation, we obtained data on inflammatory markers including neutrophil-lymphocyte ratio (NLR), derived (d)NLR, lymphocyte-monocyte ratio (LMR), platelet-lymphocyte ratio (PLR), a combination of platelet count and NLR, and prognostic nutritional index (30).

\section{Statistical analysis}

Statistical analyses were performed with SPSS v23 (SPSS Inc., Chicago, IL, USA) or R v3.60 software. Data are presented as mean \pm standard deviation. Comparisons between 2 groups were carried out with the $t$ test or chisquared test. Kaplan-Meier survival plots were generated along with the log-rank statistic using the survival package of R software.

We selected prognosis-related clinical parameters by univariate Cox proportional hazards regression (CPHR) analysis using the survival package of $\mathrm{R}$ software. CPHR is the most commonly used approach for analyzing survival data but is not suitable for multidimensional datasets (31). Therefore, using the glmnet package of $\mathrm{R}$ software, we applied the least absolute shrinkage and selection operator (LASSO) method for variable selection and shrinkage, which reduced coefficients toward zero along with the variance of these estimates (32). Finally, we constructed a model based on multiple clinical parameters identified by 
Table 1 Clinical characteristics of patients

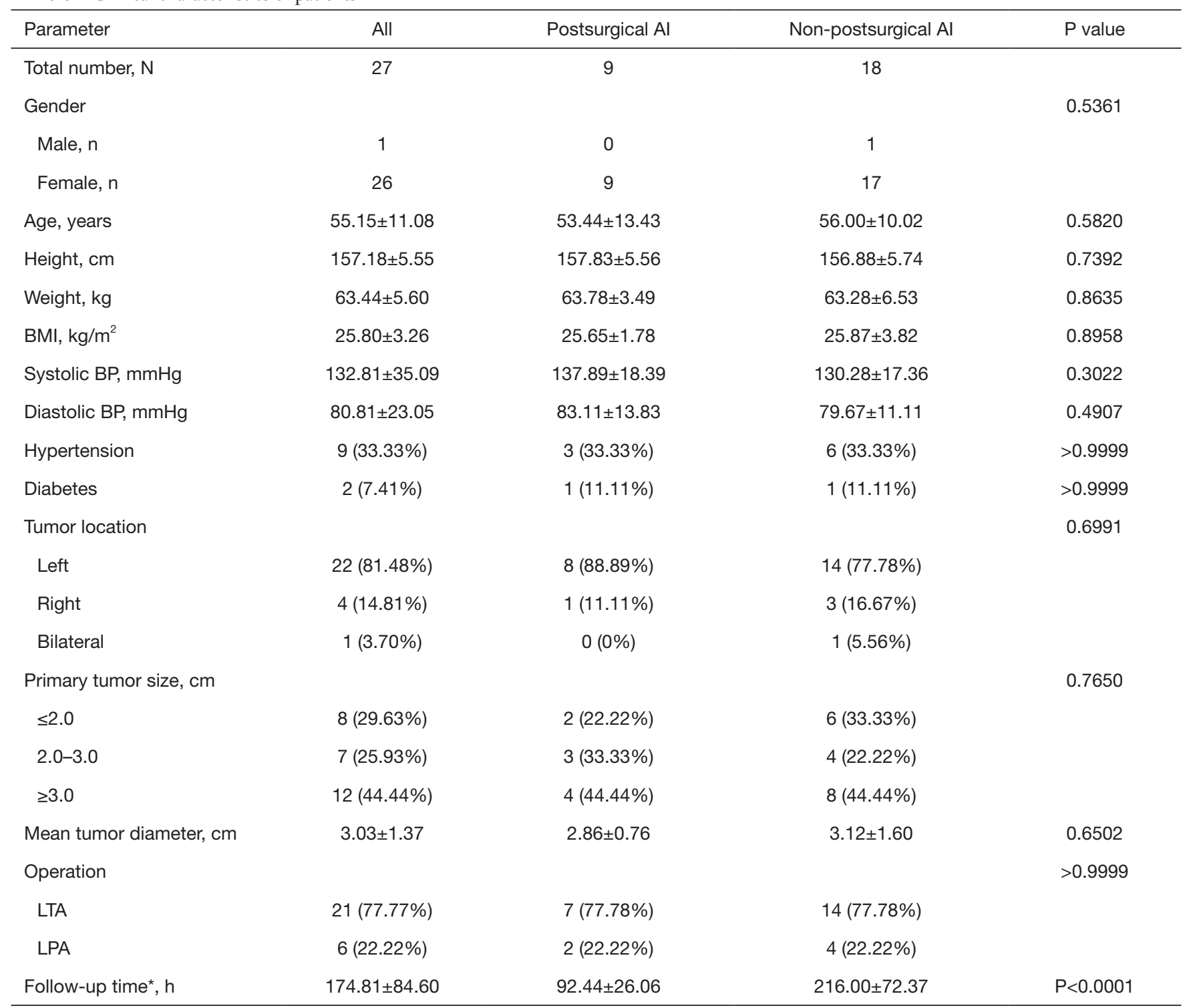

Data are shown as mean \pm SD or number (\%) unless otherwise indicated. *, from the time of operation to the time of discharge or replacement therapy. Al, adrenal insufficiency; BMI, body mass index; BP, blood pressure; LPA, laparoscopic partial adrenalectomy; LTA, laparoscopic total adrenalectomy.

the LASSO method and multivariate CPHR to predict the therapeutic schedules of patients with SCS following adrenalectomy, which was visualized as a nomogram using the rms package of $\mathrm{R}$ software. A time-dependent receiver operating characteristic (ROC) curve and calibration curve were generated to assess the predictive performance of our model using the time ROC and rms packages, respectively, of $\mathrm{R}$ software. $\mathrm{P}$ values $<0.05$ were considered statistically significant except in univariate CPHR analysis, in which the significance level was set as $\mathrm{P}<0.1$.

\section{Results}

\section{General characteristics of the study population}

Based on the above inclusion criteria, 27 patients diagnosed with SCS were enrolled in the study; their demographic characteristics are shown in Table 1. Most patients were female $(96.30 \%, 26 / 27)$ and had left adrenal 
Table 2 Hormone levels of patients at different times of the day

\begin{tabular}{lcccc}
\hline Parameter & All & Postsurgical Al & Non-postsurgical Al & P value \\
\hline ACTH, $<7.2 \mathrm{pg} / \mathrm{mL}$ & & & & \\
08:00 & $20 / 27$ & $9 / 9$ & $11 / 18$ & 0.0297 \\
$16: 00$ & $21 / 25$ & $8 / 8$ & $13 / 17$ & 0.1344 \\
00:00 & $23 / 25$ & $8 / 8$ & 3118 \\
Plasma cortisol level, mmol/L & & & $359.63 \pm 143.90$ \\
08:00 & $372.84 \pm 126.43$ & $399.24 \pm 82.26$ & $285.45 \pm 181.50$ & 0.4537 \\
$16: 00$ & $303.90 \pm 163.84$ & $338.76 \pm 125.99$ & $169.23 \pm 83.74$ & 0.4411 \\
00:00 & $210.97 \pm 112.12$ & $285.17 \pm 122.01$ & $386.30 \pm 131.91$ \\
Urine cortisol, $\mu \mathrm{g} / 24 \mathrm{~h}$ & $422.65 \pm 216.79$ & $473.55 \pm 312.40$ & 0.5181 \\
\hline
\end{tabular}

Al, adrenal insufficiency; ACTH, adrenocorticotropic hormone.

gland involvement $(81.48 \%, 22 / 27)$. The proportion with hypertension and diabetes were 9/27 (AI, $\mathrm{n}=3$ and NAI, $\mathrm{n}=6$ ) and 2/27 (AI, $\mathrm{n}=1$ and NAI, $\mathrm{n}=1$ ), respectively. In all but 2 cases (both with hypertension), the maximum tumor diameter was $\geq 2 \mathrm{~cm}$.

\section{Differences in clinical parameters between NI and NAI groups}

Nine patients were diagnosed with AI after surgery based on symptoms of hypotension, hypoglycemia, fatigue, myalgia, lethargy, or fever (33). These patients were immediately given hormone RT and constituted the AI group. There were no differences in sex ratio, age $(54.44 \pm 13.42 \mathrm{vs}$. $56.00 \pm 10.02)$, body mass index (BMI) $(25.65 \pm 1.78 v s$. $25.87 \pm 3.82)$, tumor location, or mean tumor diameter $(2.86 \pm 0.76$ vs. $3.12 \pm 1.60)$ between $\mathrm{AI}$ and NAI groups $(\mathrm{P}>0.05 ;$ Table 1$)$. The distribution of surgical approaches was also similar between the 2 groups $(\mathrm{P}>0.05)$, suggesting that total adrenalectomy was not the main cause of AI. In terms of cortisol level, only plasma cortisol at midnight (00:00) differed significantly between AI and NAI groups $(\mathrm{P}=0.0098)$, while no differences were observed in plasma cortisol levels at 08:00 and 16:00 or urine cortisol level. ATCH at 08:00 but not at 16:00 or 00:00 also showed a statistically significant difference between groups $(\mathrm{P}=0.0297$; Table 2).

Glucocorticoids are a class of steroid hormones that affect inflammation, biomolecule metabolism (carbohydrate, lipid and protein), and electrolyte balance. We examined whether glucocorticoids differentially affected AI and NAI patients and found that only 1 index of inflammation- namely, NLR - differed between the AI $(2.48 \pm 0.95)$ and NAI $(1.72 \pm 0.63)$ groups $(\mathrm{P}=0.0198$; Table 3$)$. On the other hand, multiple metabolic parameters differed between AI and NAI patients including total cholesterol $(4.90 \pm 0.40$ vs. $4.28 \pm 0.80, \mathrm{P}=0.0391$ ), high density lipoprotein (HDL) (1.61 \pm 0.30 vs. $1.25 \pm 0.27, \mathrm{P}=0.0042)$, and apolipoprotein (Apo)A1 (1.63 \pm 0.19 vs. $1.37 \pm 0.26, \mathrm{P}=0.0136)$ (Table 4). There were no differences between $\mathrm{AI}$ and NAI groups in terms of glucose metabolism, as measured by fasting blood sugar $(4.99 \pm 0.33$ vs. $5.17 \pm 0.66, \mathrm{P}=0.4507)$, glycosylated hemoglobin $(\mathrm{GH})(5.64 \pm 0.48$ vs. $5.88 \pm 0.66, \mathrm{P}=0.4014)$, and DM (1/9 vs. $1 / 18, \mathrm{P}>0.9999)$. Similarly, calcium $(2.21 \pm 0.15$ vs. $2.16 \pm 1.05, \mathrm{P}=0.8892)$, sodium $(142.44 \pm 4.14$ vs. $141.89 \pm 3.49, \mathrm{P}=0.7196)$, potassium $(4.13 \pm 0.42$ vs. $4.03 \pm 0.88$, $\mathrm{P}=0.7510)$, phosphorous $(1.19 \pm 0.33$ vs. $1.20 \pm 0.34$, $\mathrm{P}=0.9426)$, and alkaline phosphatase $(60.00 \pm 23.37$ vs. $67.11 \pm 36.85, \mathrm{P}=0.6038)$ were comparable between the 2 groups. Notably, over half of SCS patients had fatty liver $(14 / 27,51.85 \%)$.

\section{Construction of a prognostic model based on clinical parameters}

In order to identify SCS patients with postoperative AI who would benefit from RT, we considered the time of surgery and time discharge or RT as the starting and end points, respectively. Parameters for which there was incomplete information such as height, weight, BMI, GH, etc. were excluded. To avoid excluding some potentially important factors, differences with a $\mathrm{P}$ value $<0.10$ were considered significant in the univariate CPHR analysis. Nine clinical 
Table 3 Inflammatory variables of patients

\begin{tabular}{|c|c|c|c|c|}
\hline Parameter & All $(\mathrm{N}=27)$ & Postsurgical Al (n=9) & Non-postsurgical AI $(n=18)$ & $P$ value \\
\hline Neutrophil count, $\times 10^{9} / \mathrm{L}$ & $3.61 \pm 1.48$ & $3.93 \pm 1.70$ & $3.45 \pm 1.37$ & 0.4335 \\
\hline Monocyte count, $\times 10^{9} / \mathrm{L}$ & $0.68 \pm 0.87$ & $0.53 \pm 0.17$ & $0.76 \pm 1.07$ & 0.5358 \\
\hline Lymphocyte count, $\times 10^{9} / \mathrm{L}$ & $1.92 \pm 0.53$ & $1.64 \pm 0.51$ & $2.06 \pm 0.50$ & 0.0548 \\
\hline Eosinophil & $0.12 \pm 0.08$ & $0.09 \pm 0.08$ & $0.13 \pm 0.07$ & 0.2219 \\
\hline Basophil & $0.04 \pm 0.03$ & $0.04 \pm 0.04$ & $0.04 \pm 0.02$ & 0.8455 \\
\hline Albumin, $\mathrm{g} / \mathrm{L}$ & $40.85 \pm 3.13$ & $40.78 \pm 1.72$ & $40.89 \pm 3.69$ & 0.9328 \\
\hline NLR & $1.97 \pm 0.82$ & $2.48 \pm 0.95$ & $1.72 \pm 0.63$ & 0.0198 \\
\hline PNI & $50.44 \pm 3.52$ & $49.00 \pm 2.14$ & $51.17 \pm 3.88$ & 0.1328 \\
\hline PLR & $139.48 \pm 52.44$ & $143.10 \pm 53.74$ & $137.67 \pm 53.25$ & 0.8054 \\
\hline
\end{tabular}

$\mathrm{Al}$, adrenal insufficiency; NLR, neutrophil-lymphocyte ratio; dNLR, derived neutrophil-lymphocyte ratio; COP-NLR, combination of platelet count and neutrophil-lymphocyte ratio; LMR, lymphocyte-monocyte ratio; PNI, prognostic nutritional index; PLR, platelet-lymphocyte ratio.

parameters were initially selected-namely, HDL, ApoA1, NLR, dNLR, total cholesterol, lymphocyte, homocysteine, eosinophil count, and platelet count (Table 5). To avoid bias from collinearity among factors, we applied the LASSO Cox regression model and penalized maximum likelihood method to select factors that could most accurately predict RT in patients. A combination of 5 clinical parameters (ApoA1, NLR, total cholesterol, platelet count, and homocysteine) were identified as the best predictors of RT (Figure 1). These were used to calculate a risk score by multivariate CPHR (C-index=0.912, $\mathrm{P}=0.004)$. Total cholesterol had the highest hazard ratio (2660.76, $\mathrm{P}=0.045)$, followed by NLR (24.60, $\mathrm{P}=0.018)$ (Figure 2 and Table 5). Elevated total cholesterol ( $\mathrm{P}=0.038)$, NLR $(\mathrm{P}=0.019)$, and ApoA1 $(\mathrm{P}<0.001)$ were correlated with postoperative treatment selection (Figure 3). Based on the median risk score (0.86), patients with SCS were stratified into lowrisk (risk score $\leq 0.86, \mathrm{n}=14$ ) and high-risk (risk score $>0.86$, $\mathrm{n}=13$ ) groups; the latter patients were more likely to require RT (Figure 3).

We developed a nomogram based on the above 5 independent RT-related markers to predict 3-, 4-, and 5-day NRT probability (Figure 4). The corresponding regression coefficients are shown in Table 5 .

\section{Prognostic performance of the developed nomogram}

The area under the ROC curve (AUC) values in the timedependent ROC curve analysis for our nomogram were 0.833 (95\% CI: 66.01-100.00\%) for 3-day NRT, 0.945 (95\% CI: 86.19-100.00\%) for 4-day NRT, and 0.967 (95\% CI: $90.80-100.00 \%)$ for 5-day NRT (Figure 5), indicating a good predictive performance for the model. This was confirmed by the calibration curve of the 5 independent RT-related markers, which showed a good fit between the nomogram-predicted probability of NRT and actual NRT (Figure 5).

\section{Discussion}

Although autonomous and uncontrolled cortisol secretion without pituitary feedback occurs in SCS, certain signs or symptoms related to hypercortisolism such as weight gain, skin atrophy, and increased facial fullness are lacking. Nonetheless, arterial hypertension, obesity, and impaired glucose tolerance/DM are more frequently observed in patients with SCS compared to the general population (29). Current treatment options for SCS include surgery or conservative treatment. The former is considered when the tumor size is $>2 \mathrm{~cm}$ or when there is hypertension or insulin 
Table 4 Biochemical parameters in patients

\begin{tabular}{|c|c|c|c|c|}
\hline Parameter & All $(\mathrm{N}=27)$ & Postsurgical Al (n=9) & Non-postsurgical AI $(n=18)$ & $P$ value \\
\hline $\mathrm{TG}, \mathrm{mmol} / \mathrm{L}$ & $1.51 \pm 1.29$ & $1.07 \pm 0.27$ & $1.73 \pm 1.53$ & 0.2151 \\
\hline LDL, mmol/L & $2.46 \pm 0.74$ & $2.81 \pm 0.49$ & $2.29 \pm 0.79$ & 0.0841 \\
\hline $\mathrm{HDL}, \mathrm{mmol} / \mathrm{L}$ & $1.37 \pm 0.32$ & $1.61 \pm 0.30$ & $1.25 \pm 0.27$ & 0.0042 \\
\hline ApoA1, g/L & $1.45 \pm 0.26$ & $1.63 \pm 0.19$ & $1.37 \pm 0.26$ & 0.0136 \\
\hline ApoB, g/L & $0.87 \pm 0.17$ & $0.94 \pm 0.11$ & $0.84 \pm 0.18$ & 0.1406 \\
\hline ApoE, mg/L & $41.74 \pm 11.81$ & $42.78 \pm 6.20$ & $41.22 \pm 13.94$ & 0.7525 \\
\hline Lipoprotein, mg/L & $152.41 \pm 155.67$ & $102.56 \pm 116.01$ & $177.33 \pm 169.57$ & 0.2469 \\
\hline FBS, mmol/L & $5.11 \pm 0.57$ & $4.99 \pm 0.33$ & $5.17 \pm 0.66$ & 0.4507 \\
\hline $\mathrm{GH}, \%$ & $5.80 \pm 0.61$ & $5.64 \pm 0.48$ & $5.88 \pm 0.66$ & 0.4014 \\
\hline Calcium, mmol/L & $2.18 \pm 1.48$ & $2.21 \pm 0.15$ & $2.16 \pm 1.05$ & 0.8892 \\
\hline Sodium, $\mathrm{mmol} / \mathrm{L}$ & $142.07 \pm 5.37$ & $142.44 \pm 4.14$ & $141.89 \pm 3.49$ & 0.7196 \\
\hline Potassium, mmol/L & $4.07 \pm 1.26$ & $4.13 \pm 0.42$ & $4.03 \pm 0.88$ & 0.7510 \\
\hline Phosphorus, mmol/L & $1.19 \pm 0.51$ & $1.19 \pm 0.33$ & $1.20 \pm 0.34$ & 0.9426 \\
\hline ALP, U/L & $64.74 \pm 53.45$ & $60.00 \pm 23.37$ & $67.11 \pm 36.85$ & 0.6038 \\
\hline
\end{tabular}

Al, adrenal insufficiency; TC, total cholesterol; TG, triglyceride; LDL, low density lipoprotein; HDL, high density lipoprotein; ApoA1, apolipoprotein A1; ApoB, apolipoprotein B; ApoE, apolipoprotein E; FBS, fasting blood sugar; GH, glycosylated hemoglobin; ALP, alkaline phosphatase.

Table 5 Results of the Cox regression analysis

\begin{tabular}{|c|c|c|c|c|c|}
\hline Parameter & \multicolumn{2}{|c|}{ Univariate CPHR } & \multicolumn{2}{|c|}{ Multivariate CPHR } & $\mathrm{R}$ \\
\hline HDL & 37.02 & 0.0107 & & - & \\
\hline ApoA1 & 141.25 & 0.0107 & 0.27 & 0.7013 & -1.3110 \\
\hline EOS & 0.65 & 0.0625 & - & - & \\
\hline NLR & 4.90 & 0.0186 & 24.60 & 0.0182 & 3.2029 \\
\hline dNLR & 3.97 & 0.0412 & - & - & \\
\hline Total cholesterol & 48.97 & 0.0538 & 2660.76 & 0.0447 & 7.8864 \\
\hline Lymphocyte & 0.18 & 0.0518 & - & - & \\
\hline
\end{tabular}

CPHR, Cox proportional hazards regression; HR, hazard ratio; ApoA1, apolipoprotein A1; EOS, eosinophil count; NLR, neutrophillymphocyte ratio; dNLR, derived neutrophil-lymphocyte ratio; PLT, platelet count. 
A

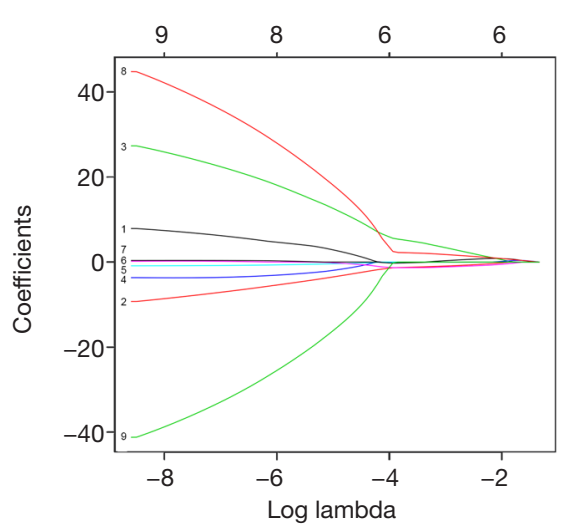

B

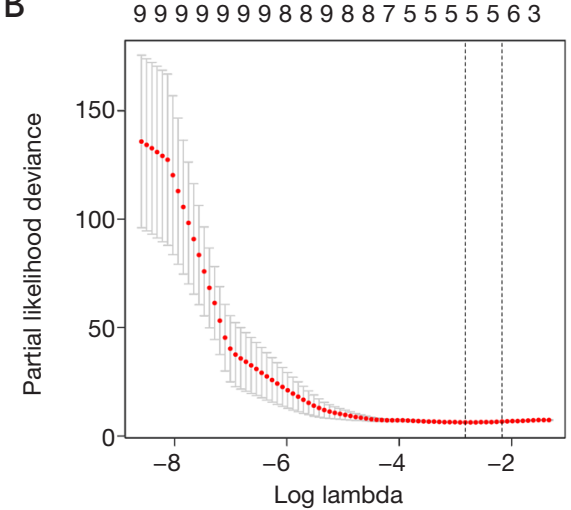

Figure 1 Best predictors of RT selected by LASSO analysis. (A) Screening path of the LASSO regression model. (B) Penalty parameter (log lambda) in the LASSO regression model. LASSO, least absolute shrinkage and selection operator.

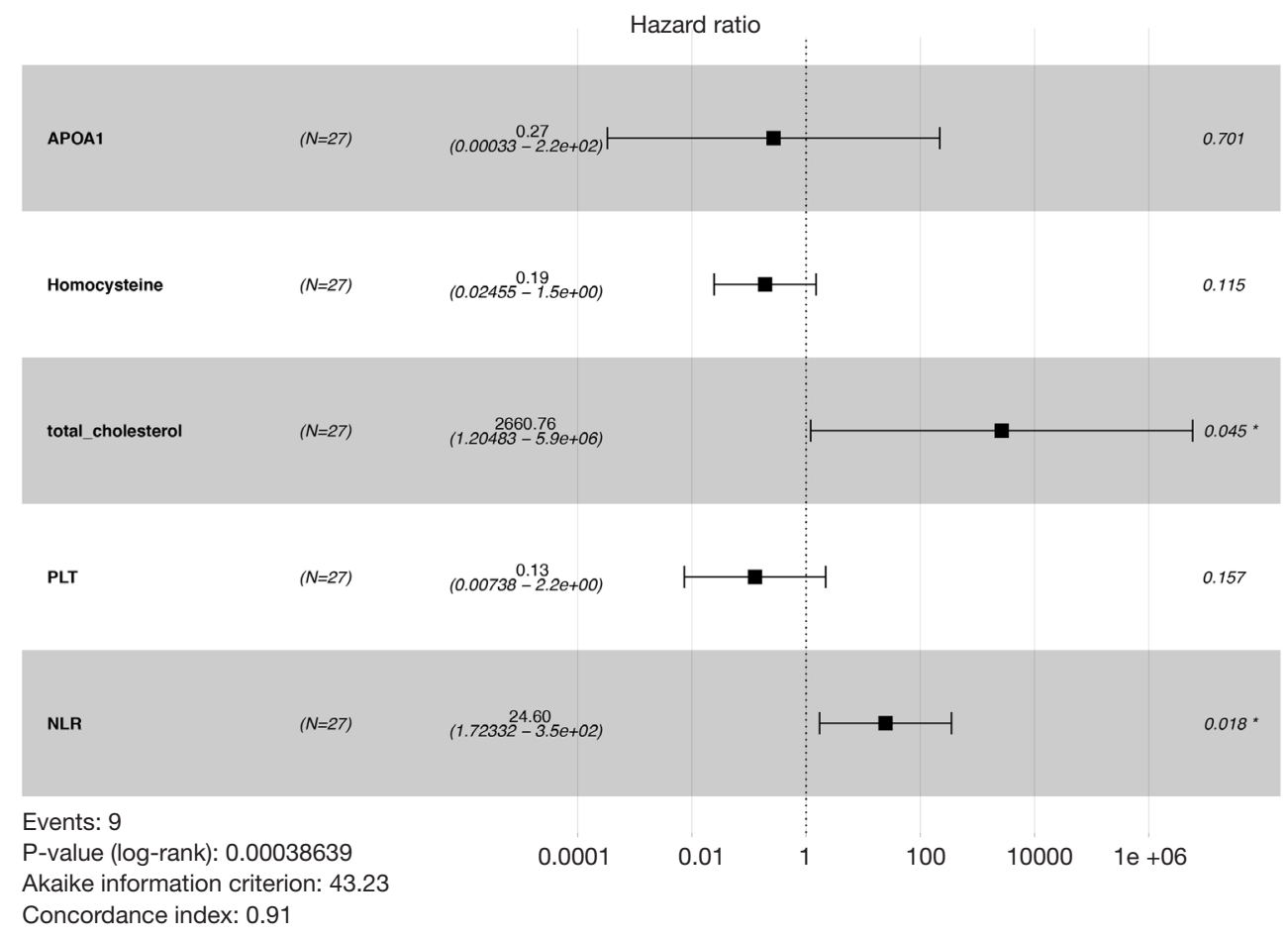

Figure 2 Forest plot of hazard ratios for analyzed parameters.

resistance/impaired glucose tolerance/DM. Laparoscopic surgery is relatively safe and reliable. All patients with SCS in this study underwent laparoscopic adrenalectomy and there were no perioperative deaths or complications or postoperative laparotomy. This is consistent with other reports that laparoscopic adrenalectomy has relatively low incidences of morbidity and mortality $(0 \%$ mortality, $6.3 \%$ morbidity, and conversion to laparotomy in $4.7 \%$ of cases) (34). The safety and reliability of laparoscopic adrenalectomy have been confirmed in other studies (35-37). Plasma ACTH, urinary free cortisol, and postdexamethasone cortisol suppressibility in patients who underwent this procedure were normalized within 1 year along with $\mathrm{DM}$ in $62.5 \%(5 / 8, \mathrm{P}=0.619)$, hypertension in $67 \%(12 / 18, \mathrm{P}=0.046)$, and hyperlipidemia in $37.5 \%(3 / 8$, $\mathrm{P}=0.619)$ of patients, as evidenced by symptom relief or a 
A
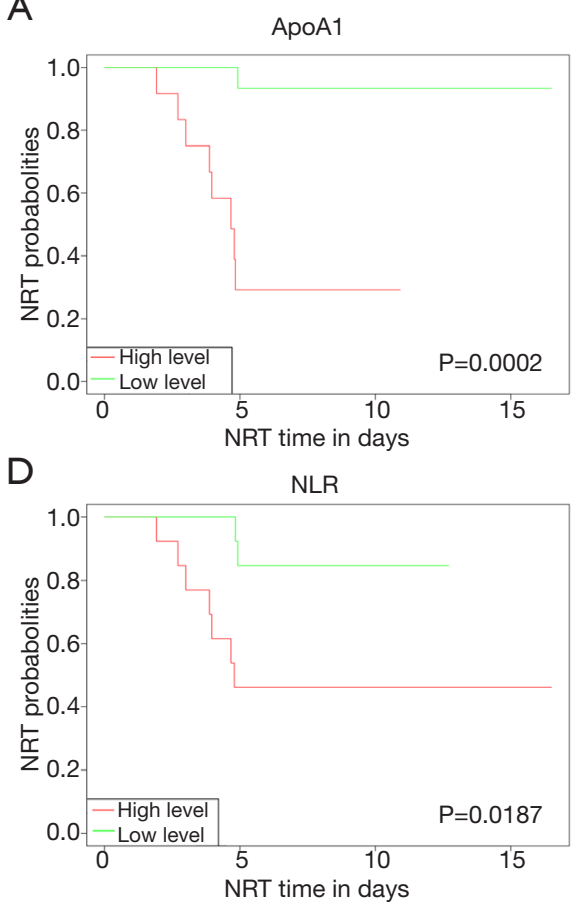

B

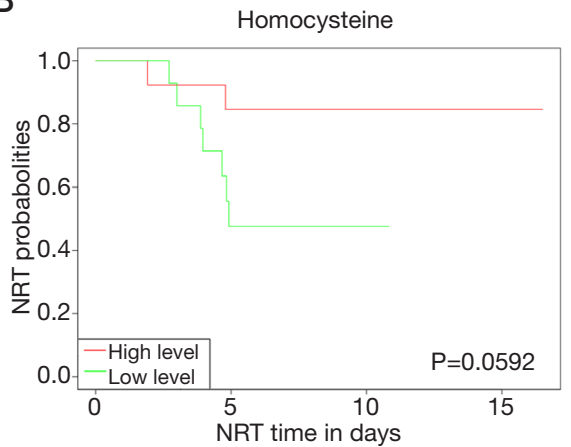

$\mathrm{E}$

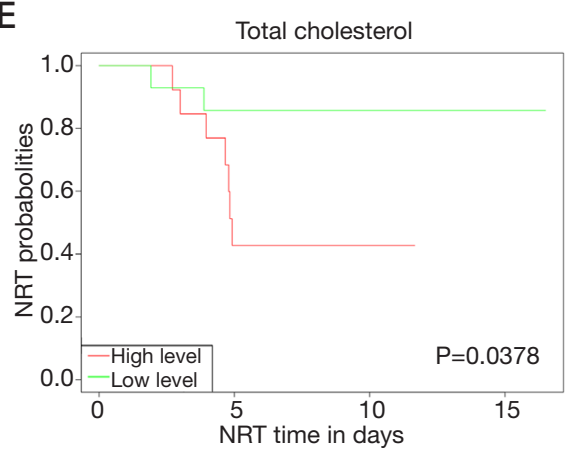

C

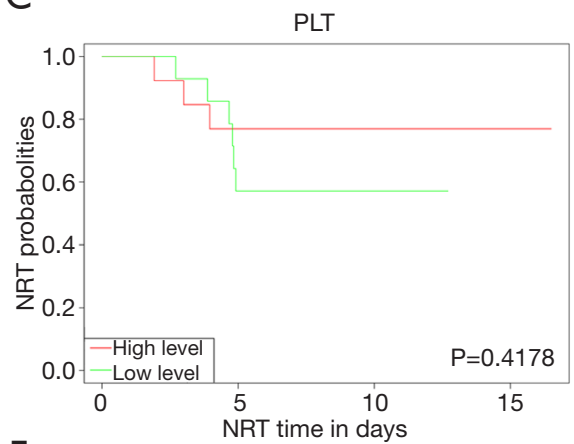

$\mathrm{F}$

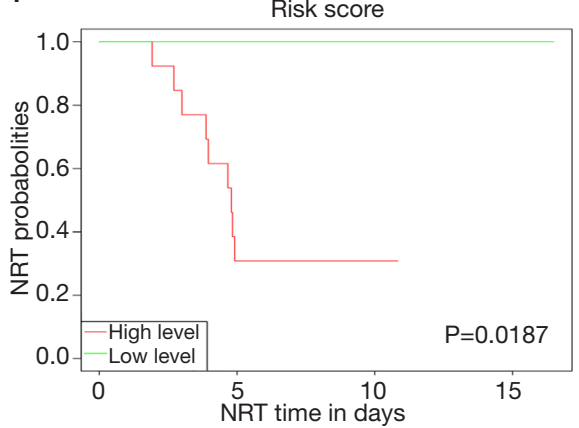

Figure 3 Kaplan-Meier curves of overall NRT time distribution in patients stratified by different indices. (A) ApoA1. (B) Homocysteine. (C) Platelet count. (D) NLR. (E) Total cholesterol. (F) Risk score. NLR, neutrophil-lymphocyte ratio.

Points

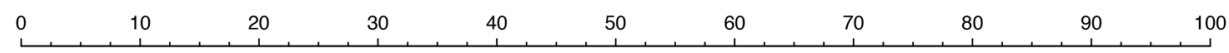

$\log _{2}(\mathrm{ApoA} 1)$

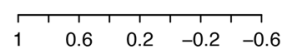

$\log _{2}$ (Homocysteine)

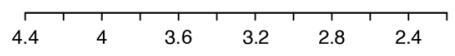

$\log _{2}$ (Total cholesterol)

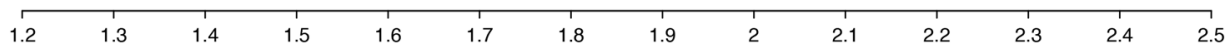

$\log _{2}$ (PLT)

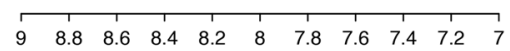

$\log _{2}$ (NLR)

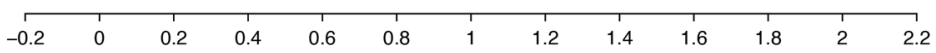

Total Points

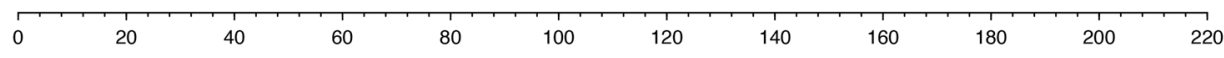

3-Day NRT

\begin{tabular}{rrr}
$0.8 \quad 0.6$ & 0.40 .2 \\
\hline & 0.4 & 0.50 .3
\end{tabular}

$\begin{array}{llllll} & 0.9 & 0.7 & 0.50 .3 & 0.1\end{array}$

4-Day NRT

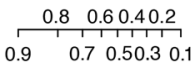

5-Day NRT

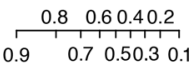

Figure 4 Nomogram based on the logarithm of 5 parameters predicting the probability of NRT after adrenalectomy. 

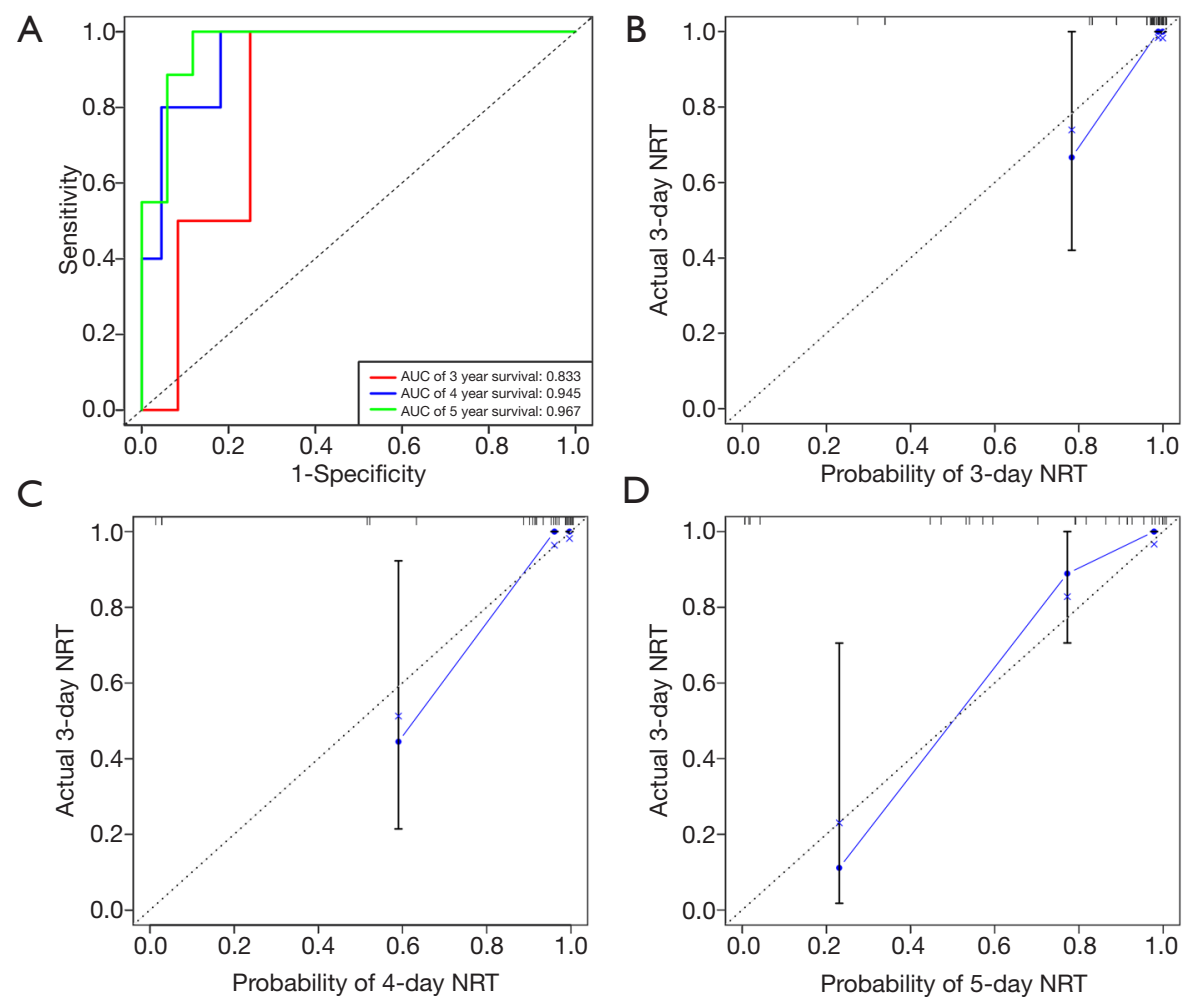

Figure 5 Evaluation of prognostic model performance. (A) ROC curve analysis. (B,C,D) Calibration curve. ROC, receiver operating characteristic.

reduction in drug dose. In contrast, patients who received conservative treatment showed no symptom improvement and in some cases even required a dosage increase (34). Other studies reported similar findings (29,38-42), suggesting that patients with SCS receive more benefit from surgery (improved hypertension, DM, and hyperlipidemia as well as weight loss) than from a conservative treatment approach.

Postoperative AI can be fatal if not treated in a timely manner $(27,43,44)$. It remains unclear whether patients with SCS who undergo adrenalectomy require RT. Overtreatment with steroids can lead to severe infections or iatrogenic CS and suppress the HPA axis, thereby delaying its postoperative recovery (28,45-47). To avoid this risk, we developed a model based on a combination of 5 preoperative clinical parameters to identify patients at risk of postoperative AI who may require RT. The model-which includes ApoA1, NLR, total cholesterol, platelet count, and homocysteineshowed good prognostic performance, with AUC values ranging from 0.833 to 0.967 for 3 - to 5 -day NRT. The risk score based on the 5 parameters was used to divide patients into low- and high-risk groups; the latter were more likely to require RT, and should thus be closely monitored following surgery. Limitations of our study included the small sample size and the fact that steroid profile was not included in the model because of a lack of clinical data, except for plasma cortisol level at 08:00. Therefore, additional studies are needed to confirm the reliability of the nomogram and validate our conclusions.

\section{Conclusions}

We developed a nomogram based on 5 parameters (ApoA1, NLR, total cholesterol, platelet count, and homocysteine) that can help to identify CSC patients who are at risk for postoperative AI and would benefit from RT. The model showed good prognostic performance and is thus a useful clinical tool that can improve the outcome of CSC patients undergoing laparoscopic adrenalectomy.

\section{Acknowledgments}

Funding: This study was supported by the Hospital Science Foundation (no. KYYJ201921) and Medical Project of Xiamen (no.3502Z20209054 and no.3502Z20209045). 


\section{Footnote}

Reporting Checklist: The authors have completed the TRIPOD reporting checklist. Available at http://dx.doi. org/10.21037/tau-20-1108

Data Sharing Statement: Available at http://dx.doi. org/10.21037/tau-20-1108

Conflicts of Interest: All authors have completed the ICMJE uniform disclosure form (available at http://dx.doi. org/10.21037/tau-20-1108). The authors have no other conflicts of interest to declare.

Ethical Statement: The authors are accountable for all aspects of the work in ensuring that questions related to the accuracy or integrity of any part of the work are appropriately investigated and resolved. The study has conformed to the provisions of the Declaration of Helsinki (as revised in 2013) and been approved by Ethics Committee of Zhongshan Hospital affiliated to Fudan University in China (No.2010-70), because of the retrospective nature of the research, the requirement for informed consent was waived.

Open Access Statement: This is an Open Access article distributed in accordance with the Creative Commons Attribution-NonCommercial-NoDerivs 4.0 International License (CC BY-NC-ND 4.0), which permits the noncommercial replication and distribution of the article with the strict proviso that no changes or edits are made and the original work is properly cited (including links to both the formal publication through the relevant DOI and the license). See: https://creativecommons.org/licenses/by-nc-nd/4.0/.

\section{References}

1. Bovio S, Cataldi A, Reimondo G, et al. Prevalence of adrenal incidentaloma in a contemporary computerized tomography series. J Endocrinol Invest 2006;29:298-302.

2. Arnaldi G, Boscaro M. Adrenal incidentaloma. Best Pract Res Clin Endocrinol Metab 2012;26:405-19.

3. Debono M, Newell-Price J. Subclinical hypercortisolism in adrenal incidentaloma. Curr Opin Endocrinol Diabetes Obes 2015;22:185-92.

4. NIH state-of-the-science statement on management of the clinically inapparent adrenal mass ("incidentaloma"). NIH Consens State Sci Statements 2002;19:1-25.
5. Mantero F, Terzolo M, Arnaldi G, et al. A survey on adrenal incidentaloma in Italy. Study Group on Adrenal Tumors of the Italian Society of Endocrinology. J Clin Endocrinol Metab 2000;85:637-44.

6. Chiodini I. Clinical review: Diagnosis and treatment of subclinical hypercortisolism. J Clin Endocrinol Metab 2011;96:1223-36.

7. Di Dalmazi G, Pasquali R, Beuschlein F, et al. Subclinical hypercortisolism: A state, a syndrome, or a disease? Eur J Endocrinol 2015;173: M61-71.

8. Chiodini I, Vainicher CE, Morelli V, et al. MECHANISMS IN ENDOCRINOLOGY: Endogenous subclinical hypercortisolism and bone: A clinical review. Eur J Endocrinol 2016;175: R265-82.

9. De Leo M, Cozzolino A, Colao A, et al. Subclinical Cushing's syndrome. Best Pract Res Clin Endocrinol Metab 2012;26:497-505.

10. Valassi E, Biller B. M, Klibanski A, et al. Adipokines and cardiovascular risk in Cushing's syndrome. Neuroendocrinology 2012;95:187-206.

11. Akaza I, Yoshimoto T, Iwashima F, et al. Clinical outcome of subclinical Cushing's syndrome after surgical and conservative treatment. Hypertens Res 2011;34:1111-5.

12. Wang D, Ji Z. G, Li H. Z, et al. Adrenalectomy was recommended for patients with subclinical Cushing's syndrome due to adrenal incidentaloma. Cancer Biomark 2018;21:367-72.

13. Scaroni C, Zilio M, Foti M, et al. Glucose metabolism abnormalities in Cushing syndrome: From molecular basis to clinical management. Endocr Rev 2017;38:189-219.

14. Iacobone M, Citton M, Scarpa M, et al. Systematic review of surgical treatment of subclinical Cushing's syndrome. $\mathrm{Br}$ J Surg 2015;102:318-30.

15. Iacobone $M$, Citton $M$, Viel G, et al. Adrenalectomy may improve cardiovascular and metabolic impairment and ameliorate quality of life in patients with adrenal incidentalomas and subclinical Cushing's syndrome. Surgery 2012;152:991-7.

16. Petramala L, Cavallaro G, Galassi M, et al. Clinical benefits of unilateral adrenalectomy in patients with subclinical hypercortisolism due to adrenal incidentaloma: Results from a single center. High Blood Press Cardiovasc Prev 2017;24:69-75.

17. Ricciato MP, Di Donna V, Perotti G, et al. The role of adrenal scintigraphy in the diagnosis of subclinical Cushing's syndrome and the prediction of post-surgical hypoadrenalism. World J Surg 2014;38:1328-35.

18. Morelli V, Minelli L, Eller-Vainicher C, et al. Predictability 
of hypoadrenalism occurrence and duration after adrenalectomy for ACTH-independent hypercortisolism. J Endocrinol Invest 2018;41:485-93.

19. Berr CM, Di Dalmazi G, Osswald A, et al. Time to recovery of adrenal function after curative surgery for Cushing's syndrome depends on etiology. J Clin Endocrinol Metab 2015;100:1300-8.

20. Lee SH, Song KH, Kim J, et al. New diagnostic criteria for subclinical hypercortisolism using postsurgical hypocortisolism: The Co-work of Adrenal Research study. Clin Endocrinol (Oxf) 2017;86:10-8.

21. Eller-Vainicher C, Morelli V, Salcuni A. S, et al. Post-surgical hypocortisolism after removal of an adrenal incidentaloma: Is it predictable by an accurate endocrinological work-up before surgery? Eur J Endocrinol 2010;162:91-9.

22. Fassnacht $M$, Arlt W, Bancos I, et al. Management of adrenal incidentalomas: European Society of Endocrinology Clinical Practice Guideline in collaboration with the European Network for the Study of Adrenal Tumors. Eur J Endocrinol 2016;175: G1-34.

23. Di Dalmazi G, Berr C. M, Fassnacht M, et al. Adrenal function after adrenalectomy for subclinical hypercortisolism and Cushing's syndrome: A systematic review of the literature. J Clin Endocrinol Metab 2014;99:2637-45.

24. Ortiz DI, Findling JW, Carroll TB, et al. Cosyntropin stimulation testing on postoperative day 1 allows for selective glucocorticoid replacement therapy after adrenalectomy for hypercortisolism: Results of a novel, multidisciplinary institutional protocol. Surgery 2016;159:259-65.

25. Abdelmannan D, Chaiban J, Selman WR, et al. Recurrences of ACTH-secreting adenomas after pituitary adenomectomy can be accurately predicted by perioperative measurements of plasma ACTH levels. J Clin Endocrinol Metab 2013;98:1458-65.

26. El Asmar N, Rajpal A, Selman W. R, et al. The value of perioperative levels of ACTH, DHEA, and DHEA-S and tumor size in predicting recurrence of Cushing disease. J Clin Endocrinol Metab 2018;103:477-85.

27. Zeiger MA, Thompson GB, Duh QY, et al. American Association of Clinical Endocrinologists and American Association of Endocrine Surgeons Medical Guidelines for the Management of Adrenal Incidentalomas: Executive summary of recommendations. Endocr Pract 2009; 15:450-3.

28. Wang D, Li HZ, Zhang YS, et al. Is prophylactic steroid treatment mandatory for subclinical Cushing syndrome after unilateral laparoscopic adrenalectomy? Surg Laparosc Endosc Percutan Tech 2019;29:31-5.

29. Reincke M. Subclinical Cushing's syndrome. Endocrinol Metab Clin North Am 2000;29:43-56.

30. Pinato DJ, Shiner RJ, Seckl MJ, et al. Prognostic performance of inflammation-based prognostic indices in primary operable non-small cell lung cancer. Br J Cancer 2014;110:1930-5.

31. Simon R, Altman DG. Statistical aspects of prognostic factor studies in oncology. Br J Cancer 1994;69:979-85.

32. Meehan AJ, Latham RM, Arseneault L, et al. Developing an individualized risk calculator for psychopathology among young people victimized during childhood: A population-representative cohort study. J Affect Disord 2020;262:90-8.

33. Bornstein SR, Allolio B, Arlt W, et al. Diagnosis and treatment of primary adrenal insufficiency: An endocrine society clinical practice guideline. J Clin Endocrinol Metab 2016;101:364-89.

34. Toniato A, Merante-Boschin I, Opocher G, et al. Surgical versus conservative management for subclinical Cushing syndrome in adrenal incidentalomas: A prospective randomized study. Ann Surg 2009;249:388-91.

35. Hensman C, Lionel G, Hewett P, et al. Laparoscopic live donor nephrectomy: The preliminary experience. Aust $\mathrm{N}$ Z J Surg 1999;69:365-8.

36. Dralle H, Scheumann GF, Nashan B, et al. Review: Recent developments in adrenal surgery. Acta Chir Belg 1994;94:137-40.

37. Guazzoni G, Montorsi F, Bergamaschi F, et al. Effectiveness and safety of laparoscopic adrenalectomy. J Urol 1994;152:1375-8.

38. Emral R, Uysal AR, Asik M, et al. Prevalence of subclinical Cushing's syndrome in 70 patients with adrenal incidentaloma: Clinical, biochemical and surgical outcomes. Endocr J 2003;50:399-408.

39. Tauchmanovà L, Rossi $\mathrm{R}$, Biondi $\mathrm{B}$, et al. Patients with subclinical Cushing's syndrome due to adrenal adenoma have increased cardiovascular risk. J Clin Endocrinol Metab 2002;87:4872-8.

40. Bernini G, Moretti A, Iacconi P, et al. Anthropometric, haemodynamic, humoral and hormonal evaluation in patients with incidental adrenocortical adenomas before and after surgery. Eur J Endocrinol 2003;148:213-9.

41. Mitchell IC, Auchus RJ, Juneja K, et al. "Subclinical Cushing's syndrome" is not subclinical: Improvement after adrenalectomy in 9 patients. Surgery 2007;142:900-5; Discussion 905.e1. 
42. Reincke M, Nieke J, Krestin GP, et al. Preclinical Cushing's syndrome in adrenal "incidentalomas": Comparison with adrenal Cushing's syndrome. J Clin Endocrinol Metab 1992;75: 826-32.

43. Terzolo M, Stigliano A, Chiodini I, et al. AME position statement on adrenal incidentaloma. Eur J Endocrinol 2011;164: 851-70.

44. Grumbach MM, Biller BM, Braunstein GD, et al. Management of the clinically inapparent adrenal mass (“incidentaloma"). Ann Intern Med 2003;138:424-9.

Cite this article as: Lin D, Lin J, Hu X, Liu Y, Zhang J, Zhang L, Jiang J, Li X, Guo J. Preoperative prognostic nomogram for prophylactic steroid treatment of patients with subclinical Cushing's syndrome. Transl Androl Urol 2021;10(1):426-437. doi: $10.21037 /$ tau-20-1108
45. Hopkins RL, Leinung MC. Exogenous Cushing's syndrome and glucocorticoid withdrawal. Endocrinol Metab Clin North Am 2005;34:371-84, ix.

46. Henzen C, Suter A, Lerch E, et al. Suppression and recovery of adrenal response after short-term, high-dose glucocorticoid treatment. Lancet 2000;355:542-5.

47. Iglesias P, Gonzalez J, Diez JJ. Acute and persistent iatrogenic Cushing's syndrome after a single dose of triamcinolone acetonide. J Endocrinol Invest 2005;28:1019-23. 